\title{
REFORMISMO, SOCIAL-DEMOCRACIA E PARTIDOS No BRASIL
}

\section{Olavo Henrique Furtado}

RESUMO: O autor discute a social-democracia no escopo partidário brasileiro. Mais especificamente, o artigo situa $\mathrm{e}$ identifica as propostas reformistas no espectro histórico-partidário da política brasileira. Em quais partidos nós poderiamos encontrar propostas mais relacionadas com um reformismo social-igualitário de caráter socialdemocrata ou socialista-democrático? $\mathrm{O}$ artigo faz uma breve retrospectiva do periodo pré-64 e depois analisa mais detidamente a configuração partidária posterior a 1979. Neste segundo periodo, principalmente com a eleição presidencial de 1994, o artigo sustenta que PT e PSDB tornaram-se peças fundamentais para se compreender o reformismo social-democrata no Brasil.

UNITERMOS: Partidos Políticos. Social-democracia. Brasil

\section{INTRODUÇĀO}

Dentre tantos debàtes que permeiam a sociedade brasileira há um que nos parece muito importante e que ganhou maior intensidade principalmente após o pleito presidencial de 1994. É a temática relativa às reformas sociais ou, se preferirmos de forma mais simples, o debate sobre o reformismo. Não que este tenha sido um assunto tradicionalmente ausente da agenda nacional e que agora começa a entrar em pauta. Pelo contrário, de forma intensiva ou não, ele foi um debate sempre presente, 
seja no governo ou fora dele (como demanda proveniente da oposição ao regime militar, por exemplo).

De forma breve, portanto, este trabalho tem o intuito de contribuir neste debate, procurando situar e identificar a proposta reformista no vultoso espectro histórico-partidário da política brasileira. Trata-se, mais especificamente, de tentar apreender em quais partidos houve - ou se ainda podem haver - propostas mais relacionadas com um reformismo social-igualitário de corte social-democrata ou socialista-democrático.

Para tanto, dividimos este trabalho em algumas partes. No item seguinte procuramos analisar rapidamente a configuração partidária pré45 a fim de demonstrar que a existência de partidos reformistas nos moldes aqui estabelecidos foi praticamente nula ou, quando muito, estes partidos apresentavam um reformismo fortemente vinculado ao populismo. Esta última possibilidade, muito evidente no período 1930-1964, mereceu um destaque especial neste trabalho.

Por fim, nos itens finais, procuramos analisar o sistema partidário formado a partir de 1979 em diante. Nossa análise procurou principalmente compreender o reformismo proposto pelo PSDB e pelo PT, partidos que atualmente nos parecem porta-vozes desta discussão. Qual é o reformismo do PSDB e do PT? - eis a pergunta que buscamos responder. Logicamente, uma resposta sob o anteparo da proposta socialdemocrata.

\section{A ConfiguraÇão Pré-45}

Uma das características peculiares ao sistema partidário brasileiro, dentre outras, se encontra na histórica volatilidade de seu espectro de partidos. Segundo Kinzo (1993, p.05-6), esta trajetória partidária, desde o Império, já enfrentou oito configurações. Com base nesta informação, e 
desconsiderando o período de 1964-65, visualizamos as sete configurações na Tabela seguinte. ${ }^{1}$

\section{Tabela I - Configurações do Sistema Partidário}

\begin{tabular}{|l|l|l|}
\hline 1 & Periodo Imperial & $1837-1889$ \\
\hline 2 & Primeira República & $1889-1930$ \\
\hline 3 & Assembléia Nac. Constituinte atć o Estado Novo (1937-45) & $1934-1945$ \\
\hline 4 & Regime Partidário & $1945-1964$ \\
\hline 5 & Regime Militar & $1965-1979$ \\
\hline 6 & Reforma Partidária atć a Nova República & $1979-1985$ \\
\hline 7 & o sistema vigente & $1985-$ \\
\hline
\end{tabular}

Apesar desta diversidade, segundo a autora, é apenas a partir de 1945, ou seja, com o fim da ditadura do Estado Novo, que o sistema partidário brasileiro ver-se-á diante de "perspectivas de modernização".

No período monárquico, a pouca representatividade do sistema era perceptível não apenas na baixa inserção da população no cenário eleitoral, tornando a política uma luta intra-elites, mas também no parlamentarismo ditado pelo Imperador (poder Moderador), que atuava como "árbitro nas disputas entre os diferentes segmentos da elite". $\mathrm{Na}$ Primeira República, se comparada ao periodo anterior, houve alguns avanços positivos, mas de fato ineficazes sob o ponto de vista da solidificação do sistema. ${ }^{2}$ Pelo contrário, a acentuada oligarquização do jogo

${ }^{1} \mathrm{Na}$ realidade, a autora enumera sete configurações. Nas suas próprias palavras, a configuração partidária de 1964-65 apenas "conservou após o golpe de 1964 o multipartidarismo anterior sob um regime militar-autoritário, até que aquele fosse extinto pelo Ato Institucional n $2 \mathrm{em}$ outubro de 1965". O periodo 1964-65 nada mais foi do que uma "sobrevida" da configuração anterior.

2 Por exemplo: presidencialismo e a extinção do Poder Moderador; eleições diretas para a presidência da República $\mathrm{c}$ fim do voto censitário, extensão do voto para os alfabetizados maiores de 21 anos. 
político, através da "política dos governadores", só veio contribuir para o agravamento da situação partidária nacional (Kinzo, 1993, p.09).

... o controle sobre o processo eleitoral não mais se ateve à eleição propriamente dita, ou seja, ao processo de votação e apuração dos votos, com todas as suas práticas viciadas. Estendeu-se à diplomação dos eleitos, eventualmente impedindo-os de tomar assento na Camara dos Deputados. Essa tarefa ficou a cargo da chamada Comissão de Verificação dos Poderes: ela é que decidia, de fato, quem eram os eleitos, barrando aqueles que não tivessem o apoio da oligarguia dominante em seus respectivos estados.

No entanto, não eram apenas estas particularidades do ordenamento político que impossibilitavam uma madura formação partidária no Brasil. Havia outras circunstâncias, sociais e econômicas, que para isso também contribuíam (Lamounier \& Meneguello, 1986, p. 26).

É fácil compreender por que, no Império e na Primeira Repuiblica, não tivemos partidos modernos. Esta expressão sugere uma atuação continua, um minimo de complexidade organizacional e burocrática, alguma orientação ideológica e certa impessoalidade no que se refere ao acesso a posiçôes de liderança. Basta lembrar que, até 1930, a grande massa da população vivia dispersa em pequenas aglomerações ou em áreas rurais; que o campesinato pobre e analfabeto, confinado nas grandes propriedades, representava uma parte substancial dessa maioria não mobilizada; e que não tivemos, nesse periodo, nem os conflitos religiosos nem os de classe que levaram à sedimentação dos primeiros sistemas partidários na Europa.

Por sua vez, o período 1930-1945 caracterizou-se pela centralização do poder na burocracia estatal e pelo conseqüente atrofiamento do poder Legislativo. O sistema de interventorias criado logo após a revolução de 30, o Departamento Administrativo do Servico Público (o DASP, fundado em 1938), seus congêneres estaduais (os “daspinbos") c, ainda, uma série 
de institutos/autarquias/gripos técnicos no decorrer dos anos 30 e início de 40 , ou seja, todo este aparato burocrático-institucional, vinculando qualquer ação política e econômica ao governo varguista, manteve-se distante de um eventual controle efetivo por parte das instâncias representativas, angariando para si as funções que deveriam competir a estas mesmas instâncias. Conforme nos coloca Maria do Carmo C. de Souza (1983, p. 83-104).

... a expansão burocrática posterior à revolução de 1930, e especialmente a verificada sob o Estado Novo, institucionalizou e legitimou a atuação direta dos interesses econômicos junto à burocracia. Inquestionavelmente, esse procedimento tornou-se a regra, e a atuagão em associações representativas de caráter autônomo e público, como a que em princípio se supõe que ocorra através dos partidos politicos, a excegão. ${ }^{3}$

É por estes aspectos que concordamos com Kinzo (1993, p. 07, $11,13)$ ao estipular o ano de 1945 como o marco-zero na possibilidade de experiências "modernas" de partido.

De fato, o partido politico, na acepfão moderna, apenas emerge quando a arena politica nacional e comum é efetivamente constituida, o que já é uma indicação da existência de um mínimo de consenso sobre o qual a disputa e a negociagão política podem ter lugar. Para que essa arena politica se constitua e os partidos se desenvolvam, é também necessário que o processo decisório das políticas públicas efetivamente en-

${ }^{3} \mathrm{~A}$ autora ainda destaca o importante papel das forças armadas nesta engenharia da centralização. Por um lado, como "avalista final de toda a estrutura baseada no binômio interventores-burocracia" e, por outro, como agente técnico-político "notadamente na formulação e implementação das decisões e planos relativos ao desenvolvimento industrial, como no caso da siderurgia e do petróleo". Ressaltamos, também, que mesmo o tenentismo, a Ação Integralista Brasileira (1932-37) e a Aliança Nacional Libertadora (1935), organizações de vital importância no período, devem ser tomadas menos como partidos constituídos do que como "clubes" ou "frentes amplas" de ação política. Mas, observemos que, segundo MENEGUELO e LAMOUNIER (1986, p.33), tanto a AIB como a ANL "configuravam finalmente o início da política de massas". 
volva o poder Legislativo, que é onde a vontade popular encontra ressonância, onde o jogo dos interesses se processa acima de tudo, onde a oposição pode ter voz. (...) Com a Constituição de 1946 que ampliou a cidadania politica e procurou assegurar a autonomia do eleitor através da criação da Justifa Eleitoral, que instaurou a liberdade de organização partidária e as premogativas do Poder Legislativo, criava-se condições para a emergência de um sistema partidário efetivo. E, de fato, partidos logo surgiram; uma arena politica nacional pela primeira vez comegou a tomar forma definida, com o Legislativo aos poucos se institucionalizando como poder atuante. 4

\section{O REFORMISMO POPULISTA (1930-1964)}

No período pré-45, como vimos, a conjuntura política e eleitoral praticamente impossibilitava a construção de autênticos "partidos modernos". Porém, não significa que propostas de corte socialistademocrático não pudessem ter aparecido.

Uma demonstração desta possibilidade nos dá Carvalho (1987, p.53). Ao deitar os olhos sobre o período republicano, por exemplo, o autor nos relata que já em 1890 houve tentativas de organizar um partido operário.

Estabeleceu-se uma disputa entre os líderes operários, como França e Silva, que lutava por um partido controlado pelos próprios operários, $e$

${ }^{4}$ (Grifo da autora). Nossa concordância diz respeito ao fato de que no período 4564, em comparação com os anteriores, as "condições" para a efetiva construção de um sistema partidário moderno comęavam a ser postas. A embrionária institucionalização do Legislativo somada à uma relativa ampliação do eleitorado, são aspectos importantes neste sentido. Se os agentes politicos conseguiram responder satisfatoriamente a estas condições não é objeto central de nossa discussão. Como a própria autora observa: "É certo que a redemocratização de 1945 conferiu ao Legislativo uma importância significativa no processo político; mas os partidos que emergiram em 1945 foram gerados e se desenvolveram sob uma estrutura politica ainda firmemente ancorada no aparato estatal". Esta relação de dependência entre sistema burocrático c partidos, sem entrarmos no mérito de se mais ou menos fortalecida, perdura até hoje.

Temáticas, Campinas, 4(8):39-62, jul./dcz. 1996 
o tenente José Augusto Vinbaes, da Marinba, que organizou um partido sob sua lideranga.

É justamente no grupo de França e Silva que podemos encontrar vestígios do que o autor chama de socialismo-democrático.

No Rio, bouve em 1892 um Congresso Socialista organizado por iniciativa de França e Silva, com a participação de 400 operários, do qual resultou o Partido Operário do Brasil. Em 1895, com a participação de Evaristo de Moraes, foi fundado um Partido Socialista Operário. Em 1899 surgiu um Centro Socialista, e em 1902 foi criado por Gustavo de Lacerda e Vicente de Souza o Partido Socialista Coletivista. Finalmente, em 1908, estivadores e cocheiros fundaram o Partido Operário Socialista, em que de novo se verificou a presença de Evaristo de Moraes. As propostas de todas estas organizações eram as do socialismo democrático, isto é, lutar por maior participação e conseguir reformas, especialmente sociais, através do mecanismo representativo. Nenbuma delas teve longa vida, muitas não chegaram a completar um ano (Carvalho, 1987. p.56, grifo nosso.)

Com a II Guerra desenhando o seu fim e a ditadura varguista enfrentando uma aguda crise, era de se esperar que os anseios por democracia se cristalizassem no período subseqüente. Mesmo que alguns partidos tenham sido criados no bojo do getulismo e da burocracia-estatal e mesmo com o negativo retrocesso em 1964, é inegável o avanço que os dezenove anos de regime democrático trouxeram em direção à consolidação do sistema partidário.

O período de 1945 - 1964 apresentava uma extensa gama de partidos. Os três maiores e mais influentes partidos da época foram o Partido Trabalhista Brasileiro (PTB), o Partido Social Democrático (PSD) e a União Democrática Nacional (UDN). Em torno deles "giravam" os demais partidos. Algumas destas siglas: Partido Comunista Brasileiro (PCB), Partido Socialista Brasileiro (PSB), Partido Social Traba- 
lhista (PST), Partido Trabalhista Nacional (PTN), Partido Rural Trabalhista (PRT), Partido Social Progressista (PSP), Partido Republicano (PR), Partido Libertador, Partido Democrata Cristão (PDC), Esquerda Democrática.

Em termos de composição política como estes partidos se dispunham? Segundo Benevides (1989, p.32),

$\mathrm{Na}$ arena bipartida encontravam-se, portanto, do lado getulista o PSD - o partido no poder; o PTB (e os pequenos partidos trabalhistas que Getúlio ironizava como "as bijuterias politicas, os partidos de Sloper") e o Partido Comunista, abrigado na sigla petebista $e$ "legitimado" pela participafão atuante na campanba "queremista" $e$ da "Constituinte com Getuilio" em 1945. Do outro lado a UDN e seus aliados, os partidos anciliares ou satélites, como o Partido Libertador (a ala "angélica" da UDN, como dizia Adaucto Lúcio Cardoso); o Partido Democrata Cristão (a UDN “confessional") $e$ os socialistas da Esquerda Democrática. O espafo do centro não era, em si, ocupado partidariamente, pois o centro era o próprio Getúlio Vargas. ${ }^{5}$

E em termos ideológicos? Observando esta lista, há um bloco de partidos - encabeçado pelo PTB - que se pretende vinculado ao trabalhismo. Um outro ponto é o PSD, o Partido Social Democrático. Contudo, é preciso fazer alguns destaques!

É uma realidade que o PTB se inspirava oficialmente, já na sua origem em 1945, como um partido trabalhista nos moldes do Labour

5 (Grifo da autora). Não deixa de haver um certo exagero, de nossa parte, ao afirmar que todos os demais partidos - excluindo-se PTB, PSD e UDN - "giravam" em torno destas siglas maiores, como se os mesmos não tivessem nenhuma liberdade programática ou bases diferenciadas. A "dependência", contudo, não deixa de ser uma realidade para alguns destes partidos menores. Mas, os motivos para tal "apoio" não podem ser generalizados. Por exemplo, o PCB necessitava de uma outra legenda (PTB) como meio de se fazer institucionalmente presente, uma vez que manteve-se na legalidade no exíguo espaço entre 1945-47. Inclusive lançou, nesta condição, "candidato próprio" à presidência da República, em 1950. Interessa-nos aqui o fato, este sim, de que todos os partidos, maiores ou menores, "giravam" em torno de Getúlio!

Temáticas, Campinas, 4(8):39-62, jul./dcz. 1996 
Party inglês. Favoreciam esta identificação os quadros intelectuais petebistas $^{6}$ que lhe conferiam um lastro teórico autêntico com o trabalhismo clássico, ou seja, ao falar de trabalhismo o PTB sabia o que estava dizendo! Havia, também, uma real base sindical que, apesar de estar sob as mãos do Estado, estava vinculada ao partido.

Mas havia alguns fatores que tornavam um tanto quanto opaca a relação do PTB com o trabalhismo.

Primeiro, como vimos, tanto o PTB como o PSD e a UDN agiam, seja pró ou contra, em função de seu "centro político": o getulismo (Benevides, 1989, p.35 e 153).

\section{Costumava-se dizer que Getúlio criou o Partido Social Democrático com a mão direita e o Partido Trabalbista Brasileiro com a mão es- querda. A União Democrática Nacional, por sua vez - e reunindo esquerda e direita - só foi criada para derrubar Getúlio e vingar a ditadura estadonovista. É nesse sentido que, por paradoxal e perverso que parefa, a UDN da "eterna vigilância" acaba sendo, também, uma criatura de Getúlio Vargas.}

No caso específico do PTB,

Esse getulismo acaba sendo identificado com o próprio trabalhismo, o que significava compensar a exirema vaguidão ideológica da pretensa doutrina com a exaltafão da obra de Getúlio "em favor dos trabalhadores".

Segundo, o populismo. Além do getulismo, tradicionalmente lembrado, o fenômeno que caracterizou a chamada "democracia populista"

6 Dos quais, os mais expressivos eram Alberto Pasqualini (1901-1960), Lúcio Bittencourt (?) e San Tiago Dantas (1911-1964).

7 Além disso, tanto PSD como a UDN "eram ambos partidos da ordem, defensores da mesma política agrária, da mesma politica salarial". Apesar de algumas divergências em questões relativas à intervenção estatal e ao capital estrangeiro, a polarização entre estes dois partidos se colocava em termos de ser oposição ou não a Getúlio. 
pode ser também identificado na sua vertente janista e ademarista. ${ }^{8}$ Não tendo sido exclusividade deste ou daquele partido, o populismo foi um fenômeno que circundou todo o nosso passado político (desde 1930) e que, de alguma forma, ainda se reproduz na presente política partidária brasileira.

Em sua análise comparativa sobre a Europa e a América Latina, Williams (1984, p. 181) ressalta a inicial "aversão" da social-democracia européia pelos fenômenos populistas latino-americanos. Segundo a autora,

Una necessidad bistórica, el "populismo", no es entendido como tal por la socialdemocracia europea que sólo ve en aquello 'un nuevo tipo de dictadura basada en la demagogia nacionalista y tratando de lograr el apoyo de la clase trabajadora con una mezcla de incentivos de antiextranjerismo y ofertas materiales, y que llegó a su culminación sólo después de la Segunda Guerra Mundial'.?

8 Tanto Getúlio Vargas (1883-1954), como Ademar de Barros (1901-1969) e Jânio Quadros (1917-1992) representaram personalidades inspiradoras para qualquer estudo sobre partidos e populismo no Brasil. No entanto, este trabalho passa ao largo do tema, visando com isso não sobrecarregar o que por nós foi estabelecido. De forma breve, apesar das enormes variâncias que este conceito produz (peronismo, getulismo e até elementos do castrismo e do fascismo) poderiamos separar algumas características que evidenciariam o populismo: fenômenos de massa; mitificação do conceito de "povo" em detrimento do conceito de "classe"; a figura de um líder-herói, defensor deste mesmo "povo"; eventualmente, um forte sentimento nacional; e, uma politização "marginal" via-cooptação popular (muitas vezes traduzida pelo sentimento anti-partidário e antiinstituições políticas). [v. Populismo, in BOBBIO, N. Dicionário de Política, 1991].

9 "Era tal la aversión de la socialdemocracia europea a este tipo de régimen, y especialmente al de Perón, gien reprimió a su única fuerza relativamente importante en América Latina (el Partido Socialista de Argentina), que aquella corriente politica europea no sólo lanzó críticas (a menudo justiticadas) contra Perón en sus publicaciones editadas en Londres en esas fechas, sino que el historiador socialdemócrata británico Cole llegaria a decir: 'cuando el fascismo y el nacionalismo se alian cada vez más estrechamente en estos movimientos a los que se llamaron más tarde peronismo...' [A autora cita nestes fragmento: COLE, G. D. H. Historia del Pensamiento Socialista, v. VI, p. 272 e 286]. A autora alerta, porém, que "muchos elementos en el movimiento 'populista' eran iguales a los del movimiento obrero europeo". Na realidade, a necessidade da 
Retornando um pouco, podemos dizer que se houve, como de fato houve, alguma posição reformista entre 1930 e 1964, este reformismo nos pareceu, de acordo com a literatura consultada, encoberto por uma espessa nuvem populista. Este reformismo-populista contribuiu para inserir a classe trabalhadora naquilo que Paulo Sérgio Pinheiro chamou de "normatização através da representação".

Notáveis constituiram partidos de quadros para a classe trabalbadora, normatizando-a através da representafão. Assim foram os diversos trabalhistas e social-democratas entre os golpes de estado de 1930 e de 1964. A emergência da classe operária no Parlamento que ocome na Europa, com a fundafão dos partidos socialistas no final do século $X I X$, e o efetivo alargamento da democracia, ainda não haviam ocorrido no Brasil na segunda metade do século XX. ${ }^{10}$

\section{Possibilidades Social-Democratas PaRa o BRASIL (1979-1994)}

Com o golpe militar de 1964 e o AI- 2 (em 1965) qualquer perspectiva mais ideológica ficou definitivamente submetida ao artificialismo ARENA/MDB e à crescente radicalização do regime. ${ }^{11} \mathrm{Na}$ ditadura mi-

social-democracia em aprofundar suas influências na América Latina será percebida somente na década de 50 , quando da criação do Secretariado Latino-Americano da Internacional Socialista (1955-1961). Antes, estas influências restringiam-se a pequenos "focos" de contato (como os socialistas argentinos e uruguaios). No Brasil, Williams relata que este secretariado da IS manteve algum contato com o Partido Socialista Brasileiro, mas não nos fornece uma data precisa. Lembremos que o PSB foi fundado em 1947 e extinto em 1965, retornando apenas em 1986. Falta-nos, por certo, elementos para determinar qual a periodicidade deste vínculo e a magnitude desta influência.

10 v. Prefácio, in MENEGUELLO, R. PT: A formação de um partido (1979-1982), p.12.

11 Porém, já no periodo de Abertura, alguns políticos mantiveram contatos formais com a Internacional Socialista. "[Em outubro de 1977] el Búro de la IS celebró, por primera vez, una reunión em Madrid. Aún si en la reunión la temática fue esencialmente sobre Sud Africa al Oriente Medio y el Sáhara Occidental, se nota la presencia de Carlos Sansores de México, en calidad de invitado, junto con otros siete funcionarios del PRI; 6 representantes del MDB de Brasil, y Guillermo Ungo del MNR de El Salvador" [v. Williams, 1984, p. 246].

Temáticas, Campinas, 4(8):39-62, jul./dez. 1996 
litar, o governo combinaria uma drástica suspensão dos direitos políticos - mantendo-se, porém, o calendário eleitoral - com o desrespeito oficial aos direitos humanos, ${ }^{12}$ além de uma ausência quase completa das (já precárias!) reformas sociais. Com o governo Geisel (1974 - 1978) e sua política de Abertura tem início a fase transitória do regime. Não sem idas e vindas, a liberalização política de meados de 70 demonstrava um regime militar já preocupado com o seu desgaste. A oposição soube aproveitar esta nova situação (Lamounier, 1989, p.39).

... governo e oposifão, encontraram espaço suficiente para, em estágios diversos, redefinirem gradativamente seus respectivos papéis, visto que cada um percebia o que poderia ganbar com a continuidade do processo [de abertura]. A oposição foi capaz de extrair importantes concessões, ao mesmo tempo em que se organizava como uma força eleitoral poderosa. O governo também se beneficiou de várias maneiras da continuidade deste processo, inclusive, o que é muito importante, com uma gradual redufão dos ônus inerentes a sua anterior postura agressiva.

A reforma partidária de 1979 é decorrente deste processo em curso de controle e concessões, deflagrado com a Abertura de Geisel e, agora, redefinido com o governo Figueiredo (1979-1984). Percebendo que o bipartidarismo lhe era desfavorável, o governo militar retorna ao pluripartidarismo. O objetivo maior era o "de dividir o principal partido oposicionista [MDB], visando manter sob controle a agenda política as condições em que seria construida a nova estrutura partidária".

$O$ binômio ARENA/MDB se desfaz em uma nova configuração: Partido Democrático Social (PDS), Partido do Movimento Democrático Brasileiro (PMDB), Partido dos Trabalhadores (PT), Partido Democrático Trabalhista (PDT) e Partido Trabalhista Brasileiro (PTB). Após seis anos, com a Nova República (1985), uma oitava configuração partidária, "fragmentada e mutante", tem início.

12 Sobretudo no governo de Costa e Silva (1967-1969) e de Emilio Médici (1969-1973). 
Diante destas duas últimas configurações, com base em alguns dos seus principais partidos, montamos a Tabela II. ${ }^{13}$

Tabela II - Formação dos Principais Partidos

\begin{tabular}{|c|c|c|}
\hline Legenda atual & Ano $^{14}$ & Origem $^{15}$ \\
\hline PMDB & 1979 & MDB \\
\hline PPR & 1993 & ARENA > PDS + PDC \\
\hline PFL & 1985 & PDS > (Frente Liberal) \\
\hline PSDB & 1988 & PMDB \\
\hline PDT & 1979 & - \\
\hline PT & 1979 & - \\
\hline novo PTB & 1981 & - \\
\hline PL & 1985 & PFL \\
\hline novo PSB & 1986 & - \\
\hline PPS & 1991 & PCB \\
\hline PC do B & 1985 (legalizado) & PCB \\
\hline
\end{tabular}

13 Esta Tabela II apresenta uma relação estimada entre algumas das atuais legendas e os seus respectivos partidos-origem. Isto se deve, sobretudo, a tão anunciada volatilidade das legendas. Mesmo porque as fusões e cisões continuam ocorrendo. É sabida, por exemplo, a ferrenha campanha do PFL (conhecida sob o nome de Projeto PFL 2000) para elevar as adesões ao partido, visando as eleições presidenciais de 1998. Este mesmo PFL, inclusive, já tem planos de mudar seu nome para Partido Social Liberal.

14 Esta coluna fornece a data da fundação da legenda atual, desconsiderando a dos seus partidos-origem. No caso do PDT estamos considerando que a Carta de Lisboa (17 de junho de 1979) é o manifesto-lançamento do partido. Cumpre ressaltar que o estatuto do PDT data de 26 de maio de 1980 . No caso do PTB, seu registro definitivo só foi conseguido em 1981, em virtude de uma disputa judicial entre Leonel Brizola e Ivete Vargas para definir a quem cabcria a legenda "PTB". A Justiça Eleitoral concedeu este direito a Ivete Vargas.

15 A coluna Origem fornece respectivamente o partido e/ou a formação que deu origem à legenda atual. No caso do PPR, sua formação atual é resultante da fusão do PDS e do PDC (Partido Democrata Cristão, de 1993). Porém, grande parte dos seus quadros tem origem anterior, na extinta ARENA. [N.A.: PPR e PP fundiram-se no atual PPB]. Por sua vez, o PFL tem sua origem primeira no PDS, tendo sido uma dissidência denominada de Frente Liberal, criada a partir da cisão com o grupo malufista em 1984. No caso do PL, sua origem está vinculada ao PFL, sendo ele um "braço menor" da expressão partidária liberal. O novo-PSB pretendeu reeditar o antigo PSB de 1947.

Tanto o PPS como o PC do B são oriundos do PCB (fundado em 1922 e na legalidade a partir de 1985). No caso do PC do B, sua existência, segundo KINZO (1993, p.67), remonta a 1958. O seu estatuto, no entanto, coloca que o PC do B foi "fundado a 25 de março de 1922 , reestruturado a 18 de fevereiro de 1962 e reorganizado como partido legal em maio de 1985", o que demonstra sua estreita ligação com o PCB. 
Vejamos algumas características destes partidos.

Primeiro, é facilmente identificável um grupo francamente favorável à tendência liberal. São eles: o Partido Progressista Reformador (PPR), o Partido da Frente Liberal (PFL) ${ }^{16}$ e o Partido Liberal (PL) ${ }^{17}$.

O Partido do Movimento Democrático Brasileiro (PMDB), como mostramos, tem sua origem no antigo $\mathrm{MDB}$, ou mais especificamente, no "movimento de resistência ao regime militar-autoritário". Com o fim da ditadura, este objetivo perde seu sentido.

Esse objetivo [resistir ao regime ditatorial] é que dava identidade ao partido. Com o tempo, porém, foi-se criando uma situação em que essa identidade passou a significar coisas diversas para os diferentes grupos que participavam do partido ou lhe davam apoio eleitoral.

Desta característica decorre uma outra que lhe é emblemática: a difícil identificação do perfil ideológico do PMDB (Kinzo, 1993, p.26).

É certo que, desde sua fundação, o PMDB incorporou um discurso reformista e popular, mas esse discurso foi sempre genérico, insuficiente para acirrar clivagens no interior do partido. Não impedia que as alas conservadoras e progressistas se julgassem representantes reais do partido.

Esta "generalidade" do PMDB dificulta sobremaneira compreender o seu "reformismo".

${ }^{16} \mathrm{O}$ PFL é o que mais solidamente se aproxima de uma proposta liberal, participando, inclusive, como observador da Internacional Liberal e mantendo relações com a Fundação Friedrich Naumann, do Partido Liberal alemão.

17 Originalmente vinculado as pequenas e médias empresas, num dos capítulos de seu programa de fundação, "A Intervenção do Estado na Econiomia", o PL delega à empresa privada toda a atividade econòmica, cabendo ao Estado apenas as atividades de "defesa do bem comum e proteção do trabalhador, dirimir conflitos, impedir a formação de monopólios e oligopólios e defender a empresa nacional", bem como responsabilizarse pela "produção de bens e serviços indispensáveis" (garantindo, por exemplo, a infraestrutura urbana e a defesa da soberania do pais).

Temáticas, Campinas, 4(8):39-62, jul./dez. 1996 
Por sua vez, apesar das tentativas de Ivete Vargas e da força eleitoral de Jânio Quadros, o novo Partido Trabalhista Brasileiro (PTB) não teve fôlego para reeditar os ideais trabalhistas do antigo PTB. $\mathrm{O}$ "trabalhismo" do atual PTB está muito mais próximo de um ideário liberal de "Estado mínimo" do que de um "Estado regulador da economia". 18

O Partido Comunista do Brasil (PC do B) é um partido que sempre portou a bandeira do stalinismo. Apesar de algumas rápidas "inferências democráticas" em sua Declaração Programática, as raízes com o "passado stalinista" são ainda muito evidentes. ${ }^{19}$

Por fim, os últimos partidos arrolados: Partido dos Trabalhadores (PT), o Partido da Social-Democracia Brasileira (PSDB), Partido Democrático Trabalhista (PDT), Partido Socialista Brasileiro (PSB) e o Partido Popular Socialista (PPS). Estes cinco partidos, de forma geral são facilmente identificáveis com uma proposta reformista.

18 "'Trabalhismo, hoje, é se preocupar prioritariamente com reajustamentos mais amplos dos menores salários, com o fortalecimento da pequena e média empresas, com a melhoria da produtividade da economia em todos os seus setores, com a abertura do pais a investimentos e tecnologias que representam contribuiçōes ao desenvolvimento, com a adequação do Estado ao tamanho necessário a que desempenhe melhor suas funções de promotor da distribuição do bem estar e tudo o mais que defendemos" [v. A Alternativa Trabalhista, de Paiva Muniz, presidente do PTB/1992]. Não deixa de ser caricatural que este novo PTB anexe, junto com o programa do partido, a carta testamento de Getúlio Vargas.

19 Ao comentar, em 1990, os acontecimentos na extinta URSS e no Leste Europeu, João Amazonas propõe, "à guisa de especulação", algumas questões sobre os motivos do fracasso: "O conceito de que o Partido dirige tudo não se teria exagerado e contraposto à liberdade de criação, de expressão e manifestação do pensamento? (...) Que lugar ocupava a liberdade para os trabalhadores e o povo no regime soviético?". E conclui ..."Há indicações e certas evidências a demonstrar que tais questões não estavam corretamente equacionadas e resolvidas na União Soviética. [mas] $\mathrm{Na}$ apreciação geral, não se pode fugir aos condicionamentos históricos que justificam a tomada de certas posições extremadas". Inclusive refere-se a uma suposta "traição revisionista" empreendida contra "o socialismo na União Soviética", numa velada tentativa de comparar as atitudes de Gorbachov ao revisionismo bersnteiniano. [v. João Amazonas, As Transformaçōes Sociais na Época da Revolução e do Imperialismo, Ed. Anita Garibaldi, 1990]. 
Tanto o PT como o PSDB têm um potencial reformista muito identificável com o socialismo-democrático ou com a social-democracia. Almeida (1990, p. 189) corretamente agrega a estes partidos mais outros dois: o PDT e o PSB.

... nunca foram tantos os social-democratas e reformistas declarados, entre os componentes das elites politicas. Pelo menos quatro partidos proclamam seu compromisso com alguma modalidade de socialismo democrático. São eles o Partido da Social-Democracia Brasileira (PSDB), o Partido dos Trabalbadores (PT), o Partido Democrático Trabalhista (PDT) e o pequeno Partido Socialista Brasileiro (PSB).

Vejamos, portanto, este bloco de partidos reformistas, mas procurando dar maior ênfase na observação do PSDB e do PT. ${ }^{20}$

\section{De REFormistas E Social-Democratas: o Debate EM AbERTo}

O vínculo do PDT com uma "modalidade de socialismo democrático" é inequívoco. Sua participação na Internacional Socialista não se restringe apenas a ser mais um "partido membro". Em 1989, o dominicano Francisco Peña Gomez, presidente do Comitê da Internacional Socialista para América Latina e Caribe, enaltecia o então candidato à presidência pelo PDT, Leonel Brizola, nos seguintes termos:

La próxima batalla del socialismo democrático en América Latina corresponderá al conpañero Leonel Brizola y al Partido Trabalhista democrático del Brasil. Su victoria debe ser la culminacion del ascenso de nuestra comiente ideologica en la nación más grande de la América Latina. ${ }^{21}$

20Infelizmente, faltam-nos dados mais concretos para analisar a proposta do PSB.

21 Presencia de America Latina y la Internacional Socialista. Nueva Sociedad 103, p. 107. 
Com a derrota do candidato, esta afirmação não se confirma. Notemos que, diferentemente de outros tempos, a Internacional Socialista reconhece que há "elementos comuns" entre o seu socialismo democrático e o populismo brizolista, a ponto de apoiá-lo!

Em 1994, na eleição seguinte, com a iminente derrota de sua candidatura, a liderança de Leonel Brizola no PDT sai do pleito ligeiramente ofuscada. ${ }^{22}$ No entanto, é inegável que o PDT, a sua maneira, continua sendo um foco socialista-democrático na América Latina. ${ }^{23}$

O PPS, Partido Popular Socialista, é um exemplo da forte guinada de alguns partidos comunistas em virtude do ocorrido na União Soviética da década de 80. Na Declarafãa Política e nas Resolufões do IX Congresso do (ainda) PCB, as palavras de ordem mais freqüentes são "socialismo" e "democracia". ${ }^{24}$

Sem pretender o abandono do marxismo e sem procurar remediar o capitalismo com uma proposta reformista, vê-se claramente que o PPS não é, na acepção mais pura do termo, um partido comunista.

As concepcões de ditadura do proletariado, do monopólio do poder pelo partido único, da predominância dos quadros sobre a participação das massas, produtos de uma época determinada, tudo isso exauriu-se. Há que buscar uma nova forma-partido, com uma nova teoria e uma nova cultura, extraida da rica berança teórica-politica do movimento socialista e da nova realidade do mundo, resgatando a melhor tradição do pensamento marxista. ${ }^{25}$

22 "O PDT tem de aprender a ouvir as urnas, que apontam para uma urgente reciclagem do partido", diz o então candidato a governador pelo Mato Grosso, Dante de Oliveira. "O Brasil do ano 2000 não é mais o da época de Getúlio Vargas". [v. Brizola terá de dividir poder no PDT, Folba de São Paulo, 18.09.1994].

23 Leonel Brizola, em janeiro de 1995, viaja ao Haiti representando o PDT diante da Internacional Socialista. [v. Brizola fica na oposição e vai a reunião no Haiti, Folha de São Paulo, 18.01.1995].

24 Lutamos pelo Socialismo com Liberdade e Democracia, Declaração Política do Partido Comunista Brasileiro, Rio de Janeiro, 02 de junho de 1991 / Nova política, partido novo, Resoluções do IX Congresso do PCB. [v. Voz da Unidade, 15.06.1991]

25 Declaração Política..., Voz da Unidade, 15.06.1991, p. 07. 
Mas e o PSDB e o PT? Estes partidos podem hoje representar autenticamente um modelo social-democrata para o Brasil?

No caso do PSDB, sua origem parlamentar, sua quase inexistente base sindical e seus fracos vínculos sociais dificultam uma identificação com o modelo social-democrata europeu. No caso do PT, esta aproximação é facilitada por sua origem classista e por suas fortes raízes sociais. ${ }^{26}$ No entanto, tanto o PT como o PSDB nasceram vinculados a um perfil de "esquerda" e "centro-esquerda". Ambos têm bases em regiōes industrializadas e urbanas. Além disso, a história de seus membros mais destacados mostra o comprometimento destes dois partidos com a democracia. ${ }^{27}$

Ao analisarmos os programas do PSDB e do PT podemos encontrar divergências, mas também similaridades (entre ambos e entre estes e a proposta social-democrata). Dois documentos do PSDB por nós analisados (o seu Programa de Fundafão e Os Desafios do Brasil e o PSDB, ambos de 1989) assinalam claramente a defesa de uma economia mista, onde o mercado é socialmente controlado e o Estado age como seu regulador. O PSDB, nestes documentos, procura se diferenciar de um "Estado forte e autoritário" e, ao mesmo tempo, não faz a apologia puritana do mercado. O Estado peessedebista está localizado entre estas duas opções, é um mediador de interesses.

Por sua vez, em termos gerais e sem levarmos em conta suas divisões internas, podemos afirmar que o PT se aproxima da socialdemocracia?

26Uma origem classista-operária e uma capilarização pela sociedade civil são atributos encontrados nos paradigmas europeus de partidos social-democratas. É o caso, principalmente, do SPD alemão $\mathrm{e}$ dos partidos socialistas escandinavos.

27Novamente recorrendo-se à social-democracia européia, pode-se perceber que o seu desenvolvimento confunde-se com a história da democracia no continente e que seu fortalecimento como proposta acompanha o progresso do capitalismo na Europa. 
Em sua origem um partido classista, anti-capitalista, com um socialismo pouco definido (ou, quando muito, definido pela negativa) e sem nenhuma aptidão social-democrata. Atualmente, apesar do discurso mais moderado e generalizado (ao povo), ainda não se compreende completamente o socialismo petista. ${ }^{28}$ Contudo, ele está muito mais palpável do que tempos atrás. O VII Encontro Nacional (1990) e o Primeiro Congresso (1991) são aqui ilustrativos. No âmbito prático, se observarmos as tendências internas ao PT, perceberemos que, mesmo divergindo sobre "meios e fins", sua porção reformista não é pequena. ${ }^{29}$

Além disso, o PT é um partido que apresenta algumas "preocupações social-democratas": defende melhorias no ambiente de trabalho e a "desmercadorização" do trabalhador, trata de maneira diferenciada as formas de propriedade e gestão, é favorável ao controle social da economia e das instituições públicas e, por fim, defende o planejamento estatal articulando-o a um "mercado socialmente orientado".

É um fato que a oratória petista remete várias vezes o partido à uma posição entre o Estado liberal e o Estado burocrático do "socialismo real". Talvez, vale observar, uma posição mais defensiva do que propriamente "programática": se antes Lula afirmava que o PT não estava procurando paliativos para o capitalismo, ${ }^{30}$ agora podemos dizer que o partido procura uma saída para os efeitos negativos que ressoam do leste europeu. A social-democracia, mesmo estigmatizada, não nos parece um "paliativo" completamente descartado.

28Esta indefinição decorre da característica presente no discurso petista de tentar se desvincular tanto do "socialismo real" como da própria social-democracia. No entanto, os documentos do PT são pouco precisos ao definir o que viria a ser este "socialismo petista". Dai a expressão socialismo pela negativa, ou seja, um "socialismo" que diz o que não é, mas não dizo qué é.

29Talvez, somente as tendências petistas situadas sob o bloco $\mathrm{Na}$ Luta PT ainda possam ser identificadas com propostas de caráter revolucionário (no sentido de "ruptura com o capitalismo").

30v. Discurso de Lula na Primeira Conveņ̧ão Nacional do PT, 1981. 
Especificamente sobre suas diferenças com a social-democracia a posição do PT ainda é um tanto quanto intolerante. Vejamos um exemplo.

... o PT não vê na social-democracia um caminho para a construção do socialismo nem tampouco uma alternativa real aos impasses da sociedade brasileira. (...) A politica socialdemocrata, do ponto de vista econômico, está baseada num Estado de Bem-Estar Social, que se apropria de parte do excedente econômico, através de politicas fiscais, e o repassa para politicas sociais destinadas a compensar as desigualdades provocadas pelo mercado. Proposta insuficiente num Pais como o Brasil [onde existem] enormes demandas populares acumuladas. (...) $A$ adoção das profundas reformas estruturais necessárias ao Brasil supõe uma ruptura radical com a ordem econômica, politica e social vigente - o que ultrapassa os limites da proposta social-democrata, que politicamente acredita na neutralidade do Estado e adota como horizonte máximo a luta por reformas no interior do próprio capitalismo. (...) A proposta social-democrática obteve relativo sucesso nas décadas que se seguiram à Segunda Guerra Mundial, quando a burguesia européia - acossada internamente pelos movimentos operários e preocupada com a expansão do bloco socialista - foi obrigada a aceitar importantes reivindicąõos políticas e sociais. (...) Hoje podemos dizer que a social-democracia não apenas perdeu a referência socialista como também se mostra incapaz de sustentar sua proposta de Estado de Bem Estar Social, imerso na crise fiscal e na regressão política. ${ }^{31}$

Analisando o fragmento, podemos concordar com o PT quando este diz que a social-democracia não é "um caminho para a construção do socialismo". No entanto, discordamos quando o texto afirma, logo em seguida, que a social-democracia não é "tampouco uma alternativa real aos impasses da sociedade brasileira". Pelo contrário, acreditamos

31Resoluções 106, 107, 108, 109 do Primeiro Congresso do PT, 1991. (grifo nosso)

Temáticas, Campinas, 4(8):39-62, jul./dcz: 1996 
que o reformismo social-democrata, mediante ajustes locais, é uma proposta muito razoável para o Brasil. ${ }^{32}$

Também temos a mesma opinião quando o PT assinala que a social-democracia "adota como horizonte máximo a luta por reformas no interior do próprio capitalismo". É um fato que, mesmo contra a vontade de alguns social-democratas europeus, é até aí que a social-democracia conseguiu chegar. No entanto, discordamos quando o partido afirma que é necessário "ultrapassar os limites da proposta social-democrata". Neste aspecto, se o "limite" ou o "horizonte" deste reformismo for, por exemplo, a Suécia, não vemos nenhuma necessidade em ultrapassá-lo!

As afirmações referentes ao "relativo sucesso" da socialdemocracia no pós-guerra podem indicar uma estratégia petista equivocada. Como assinala o texto, "a burguesia européia - acossada internamente pelos movimentos operários e preocupada com a expansão do bloco socialista - foi obrigada a aceitar importantes reivindicações políticas e sociais". Ora, se o "bloco socialista" já não parece preocupar tanto a "burguesia" como antes, a classe operária, no entanto, ainda está aí. $\mathrm{E}$ o que é mais relevante: sedenta por reformas. Ignorar isto é desviar o assunto por atalhos pouco seguros.

Por fim, o PT comete uma injustiça com os social-democratas ao afirmar que estes não conseguiram sustentar o welfare state. Da mesma forma que a construção do welfare state não é um mérito exclusivamente da social-democracia também não podemos condená-la pela crise do sistema de bem-estar. Afinal, o capitalismo contemporâneo é uma máquina tão poderosa e autônoma que está submetendo como nunca as condições nacionais às diretrizes internacionais. $\mathrm{O}$ welfare state $\mathrm{e}$ os socialdemocratas estão sob este jugo.

32Deve-se ter sempre em mente que não existe uma única proposta que seja adaptável às condições nacionais sem sofrer algum tipo de modificaçāo. Nem o liberalismo é o mesmo nos Estados Unidos e na Inglaterra, nem o comunismo europeu é igual ao comunismo latino. Por que seria diferente com a social-democracia?

Temáticas, Campinas, 4(8):39-62, jul./dez. 1996 
Gostariamos, portanto, de terminar este trabalho arriscando algumas projeções relativas a estes dois partidos especificamente: PSDB e PT.

Mesmo após as eleições de 1994, em termos de discurso e de prática política, tanto o reformismo do PSDB como do PT ainda são incógnitas.

A aliança eleitoral entre o PSDB e os setores liberais não inviabiliza um "PSDB social-democrata". A Inglaterra e a Suécia são exemplos clássicos de que uma aliança deste tipo não é uma novidade. Neste sentido, a ausência de bases sindicais no PSDB é um elemento muito mais determinante.

A grande questão é que aliança é esta? Para o PSDB, como ficou demonstrado nestes primeiros momentos do governo Fernando Henrique, a estabilização monetária é uma tarefa anterior às reformas sociais. É somente a partir delas que poderemos afirmar se há ou não uma prática social-democrata no governo do PSDB. Até lá várias situações combinadas são possiveis. Se o governo de FHC priorizar (conforme o programa original do partido) a presença social-igualitária do Estado, logicamente poderemos identificá-lo como um governo nos moldes socialdemocratas. Porém, uma inclinação como esta por parte de uma administração que se elegeu com o apoio de setores comprometidos com uma visão liberal de Estado mínimo e, ao mesmo tempo, assentados nas benesses estatais, provavelmente exigiria uma certa dose de coragem. Certamente, a aliança seria rompida e uma base de apoio "substituta" teria que ser construída.

Até o momento, certo é que a proposta do governo peessedebista é a de modernizar o capitalismo brasileiro e, novamente, aqui são possíveis duas "versões modernizadoras": a social-igualitária e a conservadora. Sobre este tema declaramos que ainda nos parece cedo para afirmações "categóricas"!

No caso do PT, onde as reformas sociais são colocadas como prioridade (mesmo cientes que elas não são possíveis em condições eco- 
nômicas instáveis) o dilema não é menor. Só que, agora, ele está mais focalizado no partido. As disputas ideológicas dentro do PT continuam dificultando a definição de seu perfil. Um partido socialista ou socialdemocrata? Um partido para a classe operária ou para a classe média ou para ambas? São questões que, se mal respondidas, refletem-se negativamente nas urnas. E o PT é também um partido de disputas eleitorais.

Garcia (1990, p.53) nos relata que quando Lula, numa de suas andanças pelo Brasil, foi perguntado se era comunista ou social-democrata, teria respondido de forma espirituosa que "era um torneiro mecânico". Tal colocação, segundo o autor, expressaria "as dificuldades e as virtudes da definição socialista petista". Hoje, passado alguns anos de história petista, talvez seja o momento de propor uma réplica ao mesmo Lula: qual torneiro mecânico, o comunista ou o social-democrata?

ABSTRACT: The author discusses the social democracy in the Brazilian party scope. More specifically, the article places and identifies the reformist proposes in the historical party spectre of the Brazilian politics. In which parties could we find proposes more connected with a social-igualitarian reformism with the characteristics of the social democracy or the democratic socialism? The articles shows a brief retrospective of the period before 1964 (the beggining of the military regime) and, after this it analyses the party configuration after 1979 (the political aperture). In this second period, mostly after the presidential election of 1994, the article sustains that the Worker's Party (PT) and the Brazilian Social-Democratic Party (PSDB) became central actors of the social-democratic reformism debate in Brazil.

KEYwordS: Political Parties. Social-Democracy. Brazil.

\section{BIBLIOGRAFIA}

ALMEIDA, M. H. T. O Reformismo Democrático em Tempos de Crise. Lua Nova, São Paulo, no 22, p. 189-205, 1990.

AZEVEDO, C. B. Leninismo e Social-Democracia: Uma Investigafãa sobre o Projeto Político do Partido dos Trabalhadores. São Paulo, 1991. Disserta- 
ção Mestrado em Ciência Política - Faculdade de Filosofia, Letras e Ciências Humanas, Universidade de São Paulo.

BENEVIDES, M. V. O PTB e o Trabalhismo: partido e sindicato em São Paulo (1945-1964), São Paulo: Brasiliense, 1989, 171 p.

BENEVIDES, M. V. O Governo Kubitschek: desenvolvimento econômico e estabilidade politica (1956-1961). Rio de Janeiro: Paz e Terra, 1979, 294 p. BUCI-GLUCKSMANN, C., Therborn, G. O Desafio Social-Democrata, Lisboa: Publicações Dom Quixote, 1983, 277 p.

CABRERA, J. R. Os Caminhos da rosa (um estudo sobre a social-democracia no Brasil). Campinas, 1994. Dissertação de Mestrado em Ciência Política, Instituto de Filosofia e Ciências Humanas, Universidade Estadual de Campinas.

CARDOSO, F. H. Perspectivas da Social-Democracia na América Latina. In: DAVID, M. D. Social Democracia Hoje . Rio de Janeiro: Fundação Teotônio Vilela, 1990, p. 07-32.

KINZO, M. D. Radiografia do Quadro Partidário Brasileiro. São Paulo: Konrad-Adenauer Stiftung, 1993, $122 \mathrm{p}$.

LAMOUNIER, B., MENEGUELO, R. Partidos Politicos e Consolidafão Democrática: o caso brasileiro. São Paulo: Brasiliense, 1986, 134 p.

CARVALHO, J. M. Os Bestializados: o Rio de Janeiro e a Repiblica que não foi. São Paulo: Companhia das Letras, 1987, 196 p.

WILLIAMS, F. La Internacional Socialista y América Latina: una visión crítica. México: Biblioteca de C. Sociales y Humanidades, 1984, 337 p.

MENEGUELO, R. PT: a formaşão de um partido (1979-1982). Rio de Janeiro: Paz e Terra, 1989, 228 p.

LAMOUNIER, B. Partidos e Utopias. São Paulo: Edições Loyola, 1989, $150 \mathrm{p}$.

GARCIA, M. A. A social-democracia e o PT. Teoria e Debate, São Paulo, no 12 , p. 45-56, 1990.

SOUZA, M. C. C. Estado e Partidos Politicos no Brasil (1930-1945). São Paulo: Editora Alfa-Omega, 1983, 178 p. 